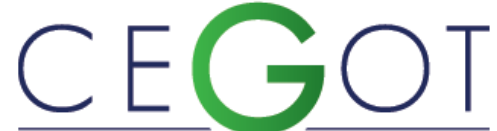

Centro de Estudos de Geografia e Ordenamento do Território
RIBEIRO, FILIPE

Universidade Federal de Juiz de Fora

Rua José Lourenço Kelmer, s/n - São Pedro. 36036-900, Juiz de Fora - Minas Gerais, Brasil filribeiro@yahoo.com.br

LIMA, FERNANDO

Universidade Federal de Juiz de Fora

Rua José Lourenço Kelmer, s/n - São Pedro. 36036-900, Juiz de Fora - Minas Gerais, Brasil fernando.lima@arquitetura.ufjf.br

\title{
Explorando métricas urbanas: desenvolvimento de uma ferramenta algorítmico- paramétrica para suporte em drenagem urbana na cidade de Juiz de Fora
}

Exploring urban metrics: development of an algorithmic-parametric tool for support in urban drainage in Juiz de Fora

Referência: Ribeiro, Filipe; Lima, Fernando (2019). Explorando métricas urbanas: desenvolvimento de uma ferramenta algorítmico-paramétrica para suporte em drenagem urbana. Revista de Geografia e Ordenamento do Território (GOT), № 18 (Dezembro). Centro de Estudos de Geografia e Ordenamento do Território, p. 126152, dx.doi.org/10.17127/got/2019.18.006

\section{RESUMO}

O desenvolvimento urbano inadequado e a drenagem descontrolada das águas de chuva vêm causando transtornos cada vez mais intensos aos centros urbanos. A adoção de ferramentas computacionais no estudo do comportamento hídrico tem sido, por sua vez, cada vez mais explorada. Neste contexto, este trabalho tem como objetivo apresentar o desenvolvimento de uma ferramenta algorítmico-paramétrica, com base nos fundamentos do Método Racional, que permita identificar o coeficiente de escoamento superficial de águas pluviais e vazão máxima de determinada bacia, na cidade de Juiz de Fora. Para a sua elaboração, foram utilizados o software Rhinoceros e o plugin Grasshopper. Como pontos positivos alcançados, destacam-se a facilidade de se fazer simulações/manipulações e os resultados satisfatórios encontrados. Como ponto frágil, aponta-se a dificuldade no reconhecimento da cobertura dos solos.

Palavras-chave: Ferramenta algorítmico-paramétrica; Parametrização; Drenagem Urbana.

\section{ABSTRACT}

Inadequate urban development and the uncontrolled drainage of rainwater have been causing intense disruption to urban centers. The adoption of computational tools in the study of water behavior has been increasingly explored. In this context, this work aims to present the development of an algorithmic-parametric tool, based on the fundamentals of the Rational Method, which allows to identify the coefficient of surface runoff of rainwater and maximum flow of a certain basin. The Rhinoceros software and the Grasshopper plugin were used for its elaboration. The positive points achieved are the ease of doing simulations 
/ manipulations and the satisfactory results found. As a fragile point, it is pointed out the difficulty in recognizing the soil cover.

Keywords: Algorithmic-parametric tool; Parametrization; Urban Drainage.

\section{Introdução}

O constante aumento da malha urbana torna a realidade das enchentes urbanas cada vez mais constantes no Brasil. O País apresentou, ao longo das últimas décadas, um crescimento significativo da população urbana, criando-se as chamadas regiões metropolitanas.

O aumento da malha urbana promove, consequentemente, o aumento de áreas desmatadas e de superfícies impermeabilizadas (cobertas por materiais como asfalto e cimento), aumentando assim os picos de vazões, tornando recorrentes as enchentes urbanas. Segundo Tucci (2006), as enchentes aumentam a sua frequência e magnitude em razão da impermeabilização do solo e podem ocorrer também por conta da construção da rede de condutos pluviais.

Apesar do longo histórico da utilização de infraestruturas no controle das águas pluviais, a maior parte das cidades brasileiras ainda não está preparada com sistemas eficientes e adequados aos parâmetros ambientais de condução e armazenamento da água pluvial (Canholi, 2005). A drenagem urbana tem sido desenvolvida com o princípio de drenar a água das precipitações o mais rápido possível para jusante, reduzindo nesses locais a perigosidade, mas produzindo o aumento da frequência e magnitude das enchentes à jusante (Araújo et al, 2000). Além disso, contribui para a contaminação do solo e das águas subterrâneas através do transporte de poluentes presentes nas vias de circulação e nas coberturas das edificações.

Tendo em vista o modelo de drenagem muitas vezes ineficaz, ainda adotado pela grande maioria das cidades brasileiras, a abordagem de novos conceitos de drenagem de águas pluviais vem sendo aprimorada, buscando-se novas práticas e novas tecnologias no combate às enchentes. O desenvolvimento urbano de baixo impacto (Low Impact Development -LID), comum nos Estados Unidos, vem ganhando espaço em novos modelos de planejamento e tem trazido vantagens e benefícios para algumas cidades de grande e médio porte ao redor do mundo. Além de combater as enchentes urbanas, tais práticas auxiliam na recarga de aquíferos, podem incorporar novos espaços de lazer para a população, proporcionam a 
melhora do microclima, servem de abrigo para a fauna, diminuem o efeito das ilhas de calor e podem possibilitar a reutilização da água retida (Cormier e Pallegrino, 2008).

A utilização de recursos computacionais no estudo das técnicas de drenagem urbana assim como da sua eficiência pode ser um aliado importante para o desenvolvimento de projetos e simulações da drenagem de áreas urbanizadas. Na maior parte das vezes utilizam-se softwares com a tecnologia SIG (sistema de informação geográfica), um sistema projetado para capturar, armazenar, manipular e apresentar todos os tipos de dados geográficos, sendo que outras tecnologias, como as baseadas na lógica algorítmico-paramétricas, são pouco ou nada exploradas nesse campo.

Este trabalho visa o desenvolvimento de uma ferramenta algorítmico-paramétrica que permita em primeiro lugar identificar o coeficiente de escoamento e a vazão de determinada área de interesse e, com isso, fornecer informações importantes para futuros projetos de drenagem urbana. É desejável que em um segundo momento, a ferramenta permita analisar a eficácia da implementação de práticas do desenvolvimento urbano de baixo impacto no combate às enchentes urbanas através da inserção de dados referentes aos coeficientes de escoamento de determinados materiais ou práticas que compõem o conjunto de ferramentas abordadas no conceito de LID.

\section{Desenvolvimento urbano de baixo impacto}

Segundo Souza et al (2012), no final dos anos 1990, a ciência passou a reconhecer o papel do solo e da vegetação (sistemas naturais de drenagem) no controle qualitativo e quantitativo de águas pluviais, ao promover a infiltração, a evapotranspiração e o contato da água com bactérias e plantas. Para tanto, utiliza-se de dispositivos de acréscimo de infiltração e do aumento de retardo do escoamento (Araújo et al, 2000). Um exemplo dessa abordagem que ganha mais força a cada dia é o conceito americano de Low Impact Development (LID), denominado no Brasil por Desenvolvimento Urbano de Baixo Impacto (DUBI).

O Desenvolvimento Urbano de Baixo Impacto é uma estratégia de manejo da terra que utiliza recursos paisagísticos naturais ou artificiais no lugar dos dispositivos tradicionais de gerenciamento de águas pluviais, e tem-se tornado cada vez mais popular nas cidades dos 
Estados Unidos como método para abordar a qualidade da água e a hidrologia urbana (JUAN et al, 2017). Segundo Pinto (2011), neste conceito o sistema de drenagem deve transportar as águas pluviais de maneira a não gerar impactos superiores aos naturais, nem a montante e nem a jusante da bacia. Ou seja, as vazões efluentes aos reservatórios devem ser equiparáveis àquelas anteriores à urbanização da bacia, eliminando ou diminuindo os impactos gerados pela ocupação urbana sobre o sistema de drenagem existente.

Os princípios dessa abordagem baseiam-se na conservação e preservação de vegetação e solo nativos, mínimo impacto na vegetação e ciclo hidrológico, através do desenvolvimento de projetos locais únicos, conservação e mimetização de processos hidrológicos naturais. Além disso, defende a educação da população e envolvimento público (Souza et al, 2012). Essa abordagem pode ser definida como um conjunto de técnicas eficientes no tratamento do escoamento superficial próximo à fonte, integrado às atividades locais e com grande vantagem econômica se relacionado aos sistemas tradicionais.

Pode-se destacar, entre as práticas de DUBI, os pisos permeáveis e os coletores de água de chuva. No presente trabalho, optou-se por simular a implantação de asfalto poroso e aplicação de telhado verde em edificações comerciais, com a finalidade de verificar seu impacto e suas contribuições nas bacias estudadas.

\section{O conceito de Métricas Urbanas (Citymetrics)}

Pretende-se, com a elaboração deste trabalho, apresentar o desenvolvimento de uma ferramenta algorítmico-paramétrica, que se relaciona com a pesquisa desenvolvida por Lima (2017), que trabalha na lógica de métricas urbanas e da elaboração de um sistema computacional, denominado como CityMetrics. O conceito de métricas urbanas, ainda segundo Lima (2017), tem por definição a aplicação de atributos mensuráveis para análises do ambiente urbano. Partindo desse pressuposto, CityMetrics é um sistema que visa a utilização de referências de cálculos (relativas a princípios objetivamente mensuráveis de teorias existentes) para a formulação de métricas geométricas e algébricas, visando avaliar e otimizar o desempenho de configurações de espaços urbanos (Lima, 2017; Lima et al., 2019). Neste contexto, optou-se por desenvolver uma ferramenta computacional, que seja 
capaz de fornecer parâmetros de análise e otimização de desempenho da drenagem de águas pluviais no ambiente urbano, a partir da inserção de atributos mensuráveis.

\subsection{Lógica algorítmico-paramétrica no contexto da drenagem urbana}

A aplicação de recursos algorítmico-paramétricos em contexto urbanístico constitui uma possibilidade relativamente nova para o planejamento e o projeto das cidades (Lima, 2017; LIMA et al., 2019). Após extensiva pesquisa, constatou-se que a aplicação destes recursos no contexto da drenagem urbana se mostra ainda mais recente e, naturalmente, pouco explorada. No entanto, recursos computacionais, sob a ótica algorítmico-paramétrica, possuem grande potencial para contribuir significativamente no suporte a solução de problemas relacionados à drenagem urbana, pois podem nos fornecer dados e diretrizes de forma precisa e dinâmica para, entre outras coisas, projetos urbanos com a finalidade de minimizar ou combater as enchentes urbanas.

Nesse sentido, optou-se por trabalhar com o software Rhinoceros e o plugin Grasshopper, pois ambos desfrutam de grande popularidade em ambientes de design tradicionais e paramétricos, proporcionando o uso generalizado de ambos entre estudantes e profissionais (Xie et al, 2011 e Lima, 2017; Lima et al., 2019).

Segundo Sanches (2017), a escolha do software Rhinoceros favorece a integração direta com programas frequentemente utilizados no Brasil para o desenvolvimento de projetos arquitetônicos (e também urbanísticos), como ArchiCAD, AutoCad e Sketchup.

\section{Princípios mensuráveis e referências de cálculo para escoamento superficial / aumento da vazão}

O aumento das áreas urbanizadas, na grande maioria das vezes, impermeáveis, ocasiona a alteração do processo de evapotranspiração e infiltração da água da chuva no solo e, consequentemente, o aumento do escoamento superficial. O escoamento superficial pode ser compreendido, de maneira simplificada, como o volume de água que escoa sobre as superfícies terrestres na unidade de tempo, e é direcionado das cotas mais altas para as cotas mais baixas, devido à atuação da gravidade. Podem manifesta-se na forma de filetes 
de água que, em seus trajetos, carregam partículas de solo devido à erosão. Juntamente com a topografia local, os filetes vão formando a rede de drenagem, que converge para cursos d'água mais estáveis, como os rios (Souza et al, 2012). Existem modalidades distintas de escoamento superficial, porém, para este trabalho não foram consideradas essas diferenças nem os processos erosivos que podem causar. Após o início da precipitação, existe um tempo de retardo do escoamento referente às perdas iniciais, como a interceptação vegetal e o tempo de resposta da bacia causado pelo deslocamento da água. Então, ocorre a elevação da vazão até o ponto máximo, onde o escoamento superficial é predominante (Pereira, 2015).

O aumento do escoamento superficial em um tempo reduzido, devido à impermeabilização do solo, se traduz em um aumento do pico de vazão. O aumento do pico de vazão é, na maioria das vezes, o responsável por eventos indesejados, como enchentes (flash floods), erosão e assoreamento de rios. De acordo com Reis et al (2012), a impermeabilização do solo acelera o escoamento, aumentando a quantidade de água que passa nos condutos e canais de drenagem urbana. Verifica-se que esta quantidade de água é tão menor quanto mais permeável for a cobertura. Já a presença de vegetação ajuda na retenção de água no solo, diminuindo o volume de água imediatamente disponível para escoamento superficial, reduzindo a velocidade de escoamento superficial e, consequentemente, a ocorrência de erosões e enchentes (Reis et al, 2012).

\subsection{A ferramenta algorítmico-paramétrica}

A utilização de ferramentas de monitoramento do uso e cobertura do solo permite que políticas públicas, direcionadas à preservação e conservação dos recursos naturais, possam atuar de forma coerente ao estabelecer medidas que minimizem os impactos causados pela urbanização estabelecida na bacia em que está inserida (Ribeiro et al., 2013).

A ferramenta aqui proposta tem por objetivo estimar o coeficiente de escoamento superficial, ou seja, o valor percentual da água que escoa sobre a superfície do solo, e a vazão máxima de determinada superfície. A vazão máxima ou vazão de pico é definida como a maior vazão atingida em um evento no qual a precipitação gera escoamento, que excede os valores habituais de vazão em determinado curso de água. A vazão máxima é um 
parâmetro muito utilizado nos cálculos de obras hidráulicas (Martins, 2017). Pretendeu-se alcançar esses resultados através de inserção de modelos digitais e cálculos matemáticos amplamente aceitos e difundidos no meio acadêmico. Uma das metodologias mais antigas e difundidas para determinar a vazão máxima de uma bacia é a do Método Racional. 0 método estabelece uma relação entre a chuva e o escoamento superficial e é utilizado para calcular a vazão de pico de determinada bacia, considerando uma seção de estudo (Tomaz, 2013).

\subsection{Método Racional}

O método racional foi apresentado pela primeira vez em 1851 por Mulvaney e estabelece uma relação entre a chuva e o escoamento superficial (deflúvio). Sua equação de estimativa de vazão considera três variáveis: a intensidade máxima média da precipitação, o coeficiente de escoamento e a área de drenagem da bacia.

O método racional deve ser aplicado somente em bacias de pequeno porte. Apesar de não haver consenso entre os estudiosos em relação às dimensões das bacias, boa parte dos autores defende que o método deve ser aplicado somente em bacias com área de drenagem inferiores a $3 \mathrm{~km}^{2}$ (300 ha).

A chamada fórmula racional é a seguinte:

$$
Q=\frac{C I A}{360}
$$

Sendo: $\mathrm{Q}=$ vazão de pico $\left(\mathrm{m}^{3} / \mathrm{s}\right) ; \mathrm{C}=$ coeficiente de escoamento superficial varia de 0 a $1 . \mathrm{C}=$ volume de escoamento/ volume total de chuva; I= intensidade média da chuva $(\mathrm{mm} / \mathrm{h})$ e $A=$ área da bacia (ha).

O coeficiente de escoamento superficial (C), também conhecido como coeficiente de escoamento de enchentes, de uma bacia representa a quantidade de água de escoamento gerada pela bacia em eventos chuvosos (Tucci, 2000). Ainda segundo Tucci (2000), o coeficiente de escoamento de uma bacia de superfícies variáveis pode ser estimado pela ponderação do coeficiente de diferentes superfícies. Considerando uma bacia urbana onde podem existir dois tipos de superfícies: permeável e impermeável é possível estabelecer que: 


$$
C=\frac{C p \cdot A p+C i \cdot A i}{A t}
$$

Onde: $\mathrm{Cp}$ é o coeficiente de escoamento de área permeável da bacia; Ap é a área da bacia com superfície permeável; Ci é o coeficiente de escoamento de uma área impermeável; Ai é a parcela da bacia com área impermeável e At é a área total da bacia.

Diferentes tipos de solo têm porosidades e coeficientes de infiltração diferentes e, consequentemente, coeficientes de escoamento diferentes. O escoamento superficial também está intimamente relacionado com as variações de declividade do terreno.

Segundo a ASCE (1969), os coeficientes de escoamento superficial podem ser avaliados como apresentado na tabela 1.

Tabela 1 - Coeficiente de escoamento superficial.

\begin{tabular}{|c|c|c|}
\hline \multirow[t]{2}{*}{ Superfície } & \multicolumn{2}{|c|}{ Coeficiente de Escoamento (C) } \\
\hline & Limites & Normal \\
\hline Pavimento: & & \\
\hline $\begin{array}{ll}\text { - } & \text { asfalto } \\
\text { - } & \text { concreto/betão } \\
\text { - } & \text { calçadas } \\
\text { - } & \text { telhado }\end{array}$ & $\begin{array}{ll}\text { - } & 0,70 \text { a } 0,95 \\
\text { - } & 0,80 \text { a } 0,95 \\
\text { - } & 0,75 \text { a } 0,85 \\
\text { - } & 0,75 \text { a } 0,95\end{array}$ & $\begin{array}{ll}\text { - } & 0,83 \\
\text { - } & 0,88 \\
\text { - } & 0,80 \\
\text { - } & 0,85\end{array}$ \\
\hline
\end{tabular}

Grama, em solo arenoso, declividade:

\begin{tabular}{|c|c|c|}
\hline $\begin{array}{ll}\text { - } & \text { baixa }(S<2 \%) \\
\text { - } & \text { média }(2 \%<S<7 \%) \\
\text { - } & \text { alta }(S>7 \%)\end{array}$ & $\begin{array}{ll}\text { - } & 0,05 \text { a } 0,10 \\
\text { - } & 0,10 \text { a } 0,15 \\
\text { - } & 0,15 \text { a } 0,20 \\
\end{array}$ & $\begin{array}{ll}\text { - } & 0,08 \\
\text { - } & 0,13 \\
\text { - } & 0,18 \\
\end{array}$ \\
\hline \multicolumn{3}{|c|}{ Grama, em solo argiloso, declividade: } \\
\hline - baixa $(S<2 \%)$ & - 0,13 a 0,17 & - $\quad 0,15$ \\
\hline - $\quad$ média $(2 \%<\mathrm{S}<7 \%)$ & - $\quad 0,18$ a 0,22 & - 0,20 \\
\hline - $\quad$ alta $(S>7 \%)$ & - 0,25 a 0,35 & - 0,30 \\
\hline
\end{tabular}

Fonte: Adaptado de ASCE (1969).

Para o cálculo da vazão máxima, é preciso definir a intensidade da precipitação. A intensidade da precipitação é obtida através de curvas de intensidade - duração frequência (IDF) do local de estudo. O cálculo da intensidade I é realizado através da equação:

$$
I=\frac{a * \operatorname{Tr}^{b}}{(t+c)^{d}}
$$


Onde: $\mathrm{I}=$ Intensidade em $\mathrm{mm} / \mathrm{h} ; \mathrm{Tr}=$ tempo de retorno em anos; $\mathrm{a}, \mathrm{b}, \mathrm{c}$ e $\mathrm{d}=$ coeficientes que dependem do local e $\mathrm{t}$ = duração em minutos.

Tomaz (2013) afirma que a duração da chuva (t) equivale ao tempo de concentração (tc) da bacia e pode ser estimado por uma série de equações empíricas estabelecidas para cada região. A seguir, destaca-se a equação de Kirpich, escolhida para ser utilizada no presente trabalho:

$$
t c=57 *\left(\frac{L^{3}}{H}\right)^{0,385}
$$

Onde: $\mathrm{tc}=$ tempo de concentração em minutos; $\mathrm{L}=$ comprimento do rio em $\mathrm{km}$ e $\mathrm{H}=$ diferença de elevação entre o ponto mais remoto da bacia e a seção principal.

De acordo com Pereira (2015), a Curva Chave de Intensidade - Duração - Frequência estabelecida para a cidade brasileira de Juiz de Fora e utilizada como referência para o presente trabalho é:

$$
I=\frac{3000 * T^{0,173}}{(t+23,965)^{0,96}}
$$

Onde: $\mathrm{t}=$ Duração da chuva em minutos, tendo sido calculada como o tempo de concentração da bacia de drenagem; T = Período de retorno em anos, ou seja, o Tempo em que se espera que o evento calculado seja igualado ou superado pelo menos uma vez. Foram escolhidos três perfis a serem trabalhados: 2 anos, 10 anos e 100 anos; 1 = Intensidade da chuva, em $\mathrm{mm} / \mathrm{h}$, com duração igual ao tempo de concentração $(\mathrm{t}$ ) e período de retorno igual a 2, 10 e 100 anos.

De posse de todos os dados necessários para alimentar as fórmulas matemáticas descritas acima, é possível identificar com certa precisão o coeficiente de escoamento e a vazão máximas das bacias de interesse, desde que respeitados seus limitadores e condições de validade. 


\section{Materiais e métodos: desenvolvimento do algoritmo e simulações para validação}

Para a pesquisa, foi criado um algoritmo capaz de fornecer o coeficiente de escoamento e a vazão máxima de uma bacia a partir de inserção de parâmetros específicos, além de permitir a simulação de diferentes realidades no contexto da bacia. O roteiro para identificar os valores referentes ao coeficiente de escoamento e vazão máximo deve seguir fórmulas matemáticas previamente apresentadas neste trabalho, além de formas geométricas que se referem ao tamanho e formato da bacia, assim como aos materiais que cobrem o solo.

Quanto à validação dos valores encontrados na ferramenta desenvolvida, optou-se por trabalhar com o Plano de Drenagem de Juiz de Fora, elaborado no ano de 2011, como referência. Nele podem encontrar-se dados sobre as sub-bacias da Região Norte do município, como seu tamanho, perímetro e densidade, além dos valores do coeficiente de escoamento superficial médio e vazão máxima de cada sub-bacia nos períodos de seca e de cheia.

\subsection{O município de Juiz de Fora}

Juiz de Fora (Figura 1) é uma cidade brasileira com população estimada pelo Instituto Brasileiro de Geografia Estatística - IBGE (2017) de 563.769 habitantes, localizada no sudeste de Minas Gerais e polo de uma extensa região que abrange a Zona da Mata Mineira e parte significativa do vizinho Estado do Rio de Janeiro (Machado e Cunha, 2011).

Da população total do município, $98,9 \%$ é considerada urbana, de acordo com dados do IBGE no ano de 2010. Ainda segundo o IBGE, em 2017 sua área territorial era de 1.435,749 $\mathrm{km}^{2}$. 

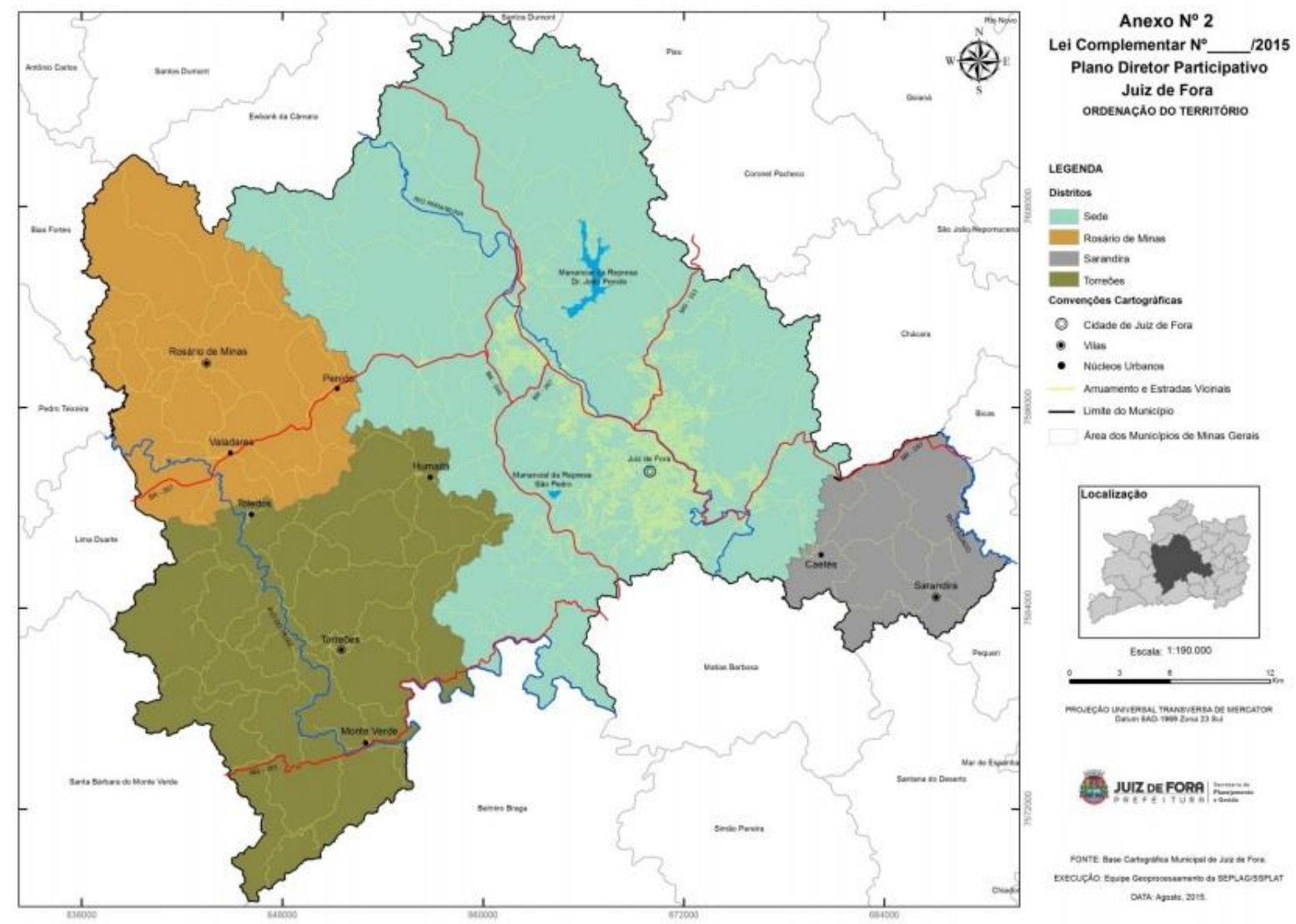

Fig. 1 - Perímetro do município de Juiz de Fora.

Fonte: Prefeitura Municipal de Juiz de Fora (2016)

Na Área Urbana do Município de Juiz de Fora, existem 156 sub-bacias de diversas dimensões (CESAMA, 2018). O processo histórico de ocupação e as modificações que ocorreram em boa parte das sub-bacias, promoveram impermeabilizações do solo, canalizações de córregos, retirada de meandros (retificação do canal) e construções em geral que ocasionam o aumento da probabilidade de ocorrência de enchentes. Segundo Souza et al (2009), a mancha urbana do município ocupa apenas $93,5 \mathrm{~km}^{2}$ (cerca de $28 \%$ da Área Urbana), o que deixa desocupados quase $72 \%$ do espaço legalmente considerado urbano.

De acordo com o Plano Diretor de Desenvolvimento Urbano (PDDU) de Juiz de Fora, a zona norte de Juiz de Fora, área de abrangência do Plano de Drenagem de Juiz de Fora (2011), é apontada como de grande potencial de expansão e adensamento.

Boa parte dos bairros da Zona Norte de Juiz de Fora sofre frequentemente com problemas relacionados às enchentes urbanas, conforme apontado no Plano de Drenagem de Juiz de Fora (2011) e noticiado regularmente nos noticiários locais. Quando considerado o potencial 
de expansão e adensamento da região, fica evidente a potencialidade de aumento de ocorrências desses fenômenos assim como da gravidade dos mesmos.

\subsection{Plano de drenagem de Juiz de Fora}

Segundo Castro et al (2011) os estudos elaborados no Plano de Drenagem de Juiz de Fora, foram desenvolvidos a partir de dados gerados em ambiente SIG (sistema de informação geográfica), utilizando o software ArcGIS da ESRI ${ }^{\circledR}$, $\operatorname{com}$ base em dados fornecidos pela Prefeitura de Juiz de Fora, o que possibilitou estabelecer as características fisiográficas das 40 sub-bacias da zona norte de Juiz de Fora (Figura 2).

A determinação das vazões máximas para diferentes períodos de retorno foi realizada utilizando o software SISHIDRO-JF, desenvolvido pelo Departamento de Engenharia Sanitária e Ambiental - ESA, da Universidade Federal de Juiz de Fora - UFJF, onde foram avaliados sete cenários diferentes para analisar o comportamento das manchas de enchentes em decorrência das mudanças nas vazões dos cursos de água da região norte do município.

A partir dos valores de vazões máximas para diferentes períodos de retorno gerados pelo sistema SISHIDRO-JF e das vazões máximas estimadas para o rio Paraibuna a partir da estação fluviométrica Chapéu D'uvas e com a base de dados geográficos gerados no software Hec-Geo_HAS e ArcGIS, foi possível alimentar o sistema de simulação HecHAS, e assim gerar as manchas de risco de enchentes (Castro et al, 2011).

No documento elaborado para o diagnóstico do plano de drenagem de Juiz de Fora não fica explícito qual a fórmula matemática utilizada para se obter os resultados através dos softwares, porém, durante a pesquisa foi possível fazer contato com autores que participaram dos estudos do de Plano do Drenagem e foi esclarecido que as fórmulas utilizadas foram as do Método Racional, havendo a necessidade de aplicar o Método Racional Modificado quando utilizados em sub-bacias maiores que $3 \mathrm{~km}^{2}$. 


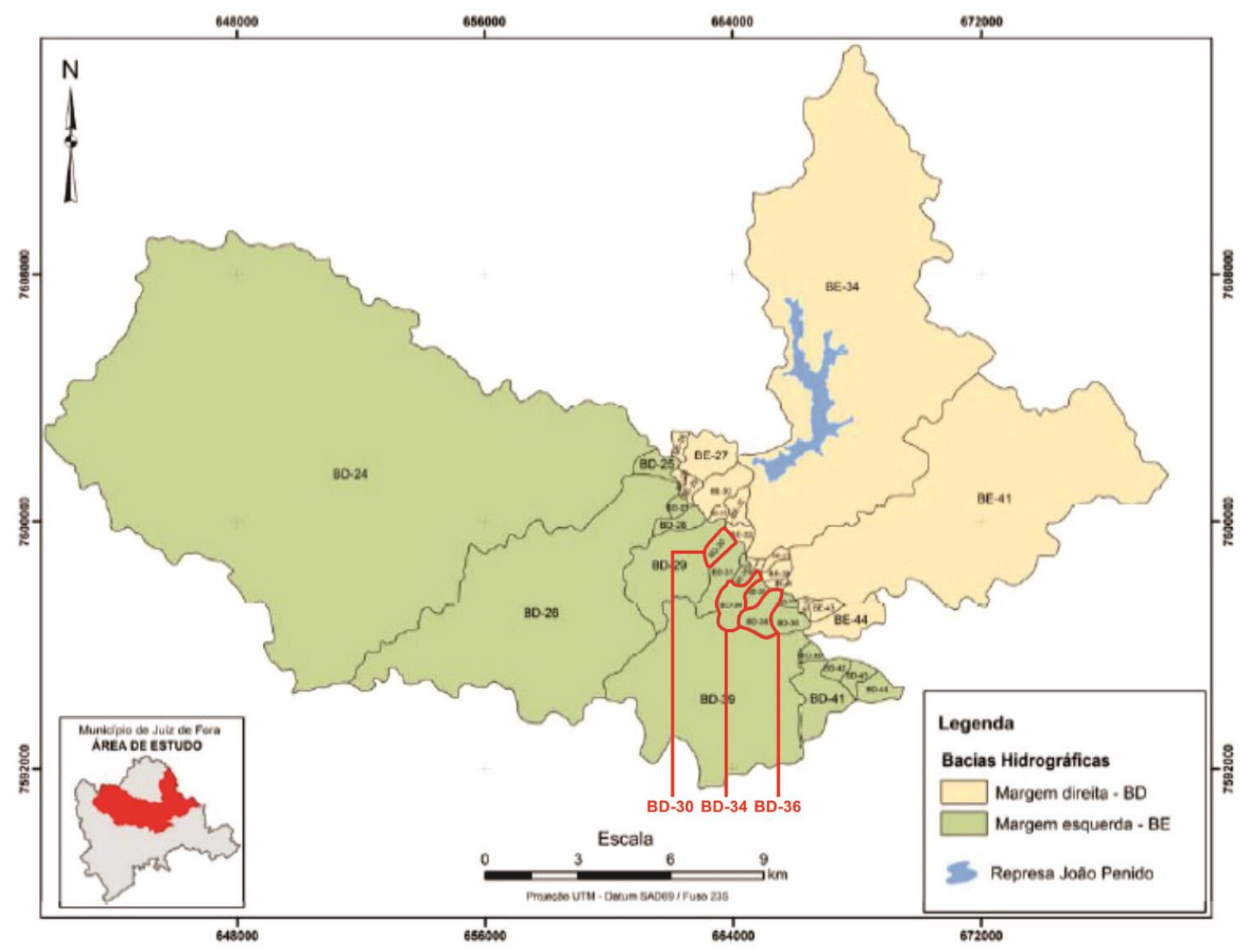

Fig. 2 - Bacias hidrográficas da Zona Norte do município de Juiz de Fora.

Fonte: Plano de Drenagem de Juiz de Fora - Zona Norte (2011)

\subsection{Construção do algoritmo e histórico de versões}

Para a construção do algoritmo, calibração e testes posteriores, foram selecionadas três sub-bacias localizadas na Região Norte do município de Juiz de Fora, às quais foram atribuídos os códigos BD-30, BD-34 e BD-36. De acordo com o Plano de Drenagem de Juiz de Fora, as sub-bacias BD-30, BD-34 e BD-36 contam com uma área de 0,67 km², 1,27 km² e 1,16 km², respectivamente. A BD-36 e BD-34 encontram-se no bairro Barbosa Lage, enquanto a BD-30 abrange o bairro Nova Era. Vale ressaltar que o diagnóstico feito para o Plano de Drenagem foi elaborado no ano de 2011, e de lá para cá a malha urbana da região aumentou.

Para a análise das sub-bacias e construção da ferramenta, é fundamental o (1) levantamento de seu perímetro, (2) reconhecimento da cobertura do solo, (3) identificação do coeficiente de escoamento dos materiais que conformam as coberturas do solo, (4) 
reconhecimento da topografia, para efeito de cálculos e, por fim, (5) a identificação da Curva Chave Intensidade - Duração - Frequência determinada para a localidade onde a ferramenta está sendo aplicada. Essas informações alimentam as formulas do método racional aplicadas nos algoritmos do software Rhonoceros conforme indicado na figura 3. Após alteração manual do coeficiente de escoamento superficial dos materiais que cobrem as bacias, os valores de escoamento superficial total e vazão máxima das bacias é gerado automaticamente e instantaneamente.

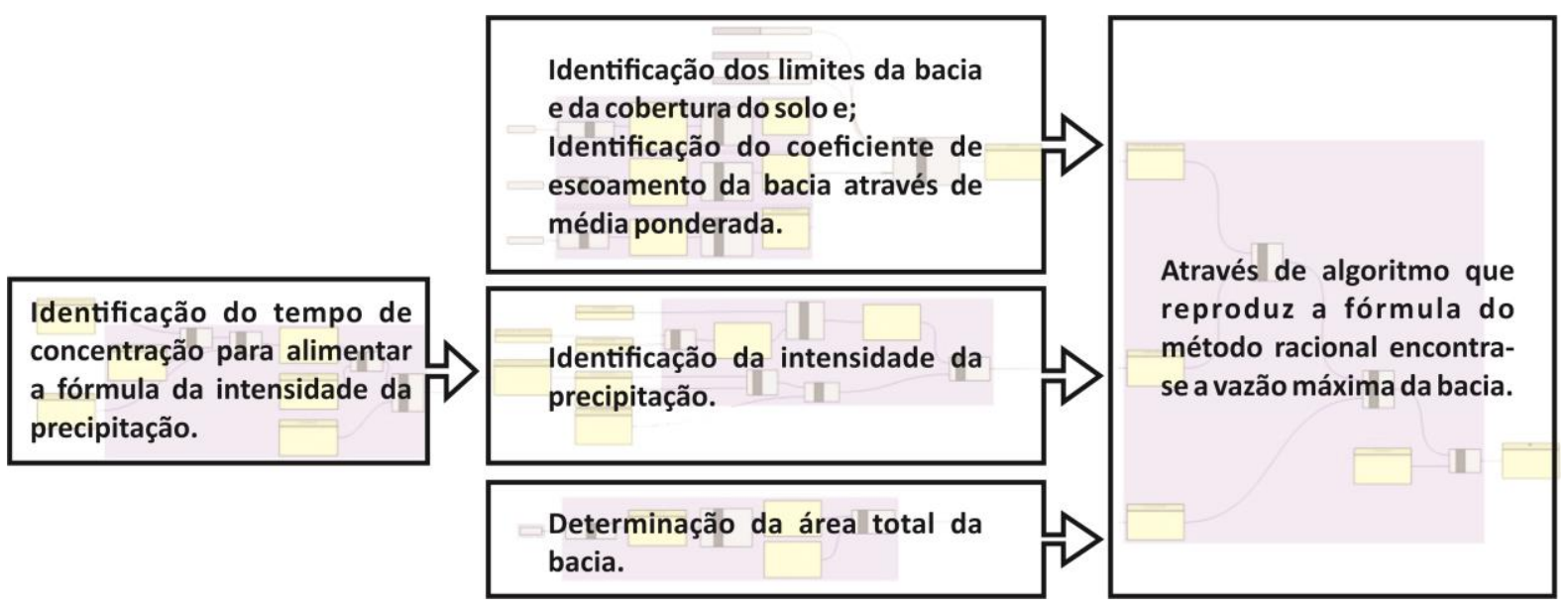

Fig. 3 - Mapa de grupos do algoritmo.

Fonte: Elaboração própria.

\subsubsection{Sub-bacia BD-36}

Para experimento inicial, foi selecionada a sub-bacia BD-36, por suas características físicas, morfológicas, e pelo seu histórico de enchentes urbanas. Para o procedimento de levantamento do perímetro das sub-bacias e o reconhecimento da cobertura dos solos, foram feitas diversas visitas ao local, assim como análises criteriosas de imagens de satélite retiradas do Google Earth, um software gratuito desenvolvido e distribuído pela empresa norte-americana Google, referentes ao ano de 2011, ano em que foi elaborado o Plano de Drenagem de Juiz de Fora. Essas imagens foram então importadas para o software AutoCAD, da Autodesk, onde foram criados sobre as imagens, quadrados de $10 \times 10$ metros, chamados de células (figura 4), conformando um grid sobre a sub-bacia, conforme estudo similar desenvolvido por Juan et al (2017). Optou-se por dividir a sub-bacia em células pela simplificação no processo de reconhecimento da cobertura do solo e, sobretudo, por 
permitir a possibilidade de verificação do coeficiente de escoamento e vazão máxima em qualquer parte da sub bacia, e não somente à jusante.
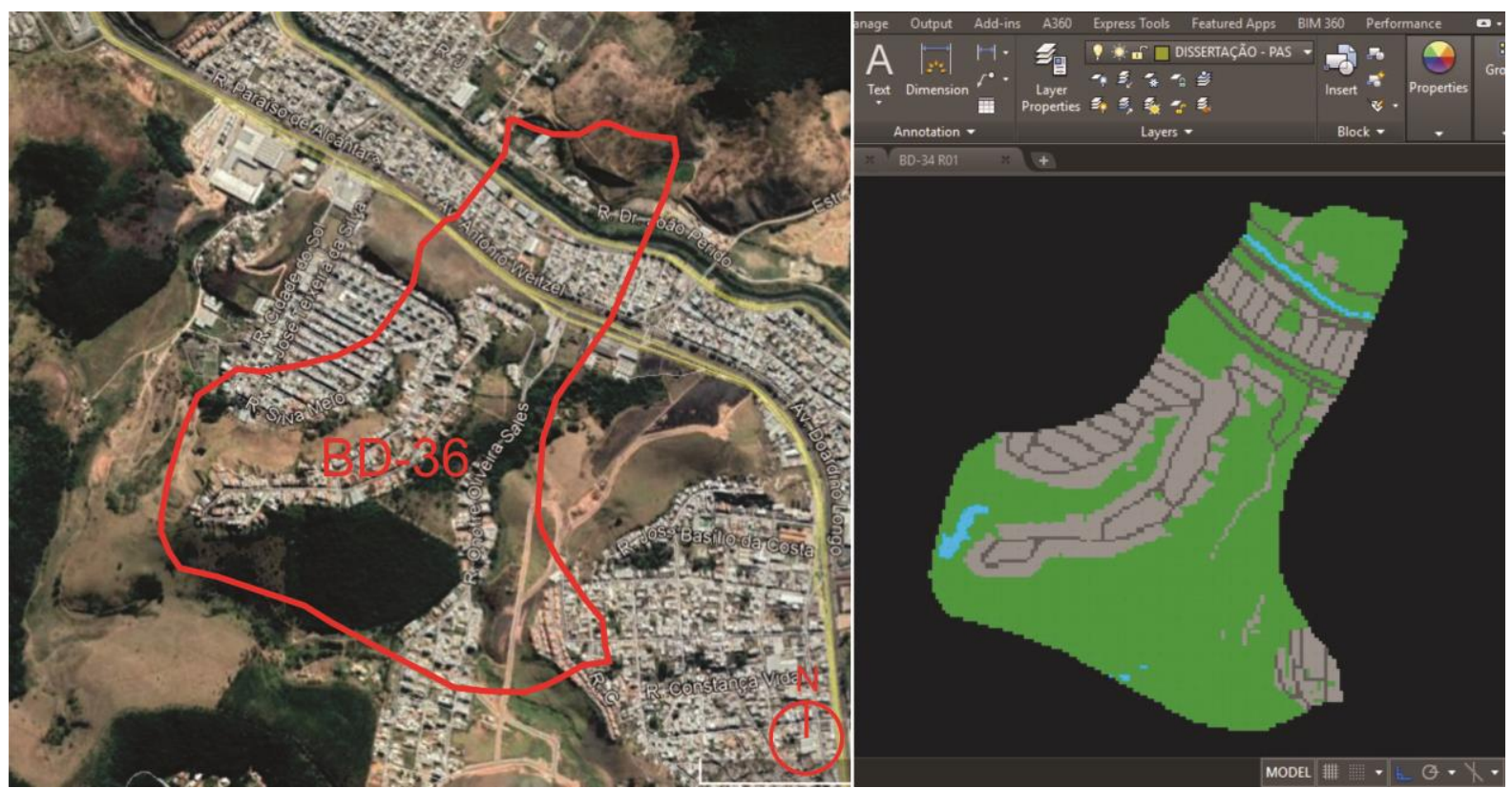

Fig. 4 - Comparativo entre imagem retirada de satélite (Google Earth) e células desenvolvidas no software AutoCAD representando as coberturas do solo da sub-bacia BD-36.

Fonte: Elaboração própria.

Dessa forma, cada célula da sub-bacia BD-36 foi caracterizada através de "layers" de acordo com a cobertura predominantemente encontrada em sua superfície (asfalto, edificações, área permeável e cursos de água). Portanto, a cobertura que ocupa a maior parte da superfície de cada célula determina o material que aquela célula representa.

Após feito o grid no software AutoCAD, o arquivo foi importado para o software de modelagem tridimensional Rhinoceros. Dentro desta plataforma foi utilizado o plugin Grasshopper. No primeiro, são fornecidos os dados do ambiente através de desenhos que servirão de suporte para as operações realizadas pelo algoritmo (desenhos das células que conformam as bacias). No segundo, o usuário complementa os inputs com os valores dos coeficientes de escoamento superficiais de cada cobertura de solo e valores que alimentam as fórmulas matemáticas para se identificar o coeficiente de escoamento total e a vazão máxima das bacias.

De acordo com o diagnóstico do Plano de Drenagem de Juiz de Fora (2011) o coeficiente de escoamento da sub-bacia BD-36 é de 0,40. O valor obtido com a ferramenta desenvolvida é de 0,42 , apresentando diferença de $5 \%$ no resultado final. Essa diferença provavelmente 
ocorre em razão da resolução da grid de 10 por 10 metros ou em razão da dificuldade de identificação da cobertura do solo em algumas partes da imagem retirada do software Google Earth, feita pelo satélite Landsat e utilizada como referência, principalmente nas áreas que conformam terrenos privados.

O valor final encontrado para vazão máxima da bacia " $Q$ " nos períodos de cheia (tempo de retorno de 100 anos) foi de 34,43 $\mathrm{m}^{3} / \mathrm{s}$. De acordo com o Plano de Drenagem de Juiz de Fora, o valor de " $Q$ " para a bacia BD-36 nos períodos de cheia é de $36,21 \mathrm{~m}^{3} / \mathrm{s}$. A diferença entre o valor encontrado pela ferramenta e o valor informado no plano de drenagem é de $4,91 \%$.

Alterando o valor do tempo de retorno para 5, equivalente a precipitações menos intensas, automaticamente o valor da intensidade da precipitação diminui, acarretando mudanças também no valor da vazão máxima " $Q$ ": $20,50 \mathrm{~m}^{3} / \mathrm{s}$. De acordo com o plano de drenagem de Juiz de Fora, o valor de " $Q$ " para os períodos de seca é de $21,60 \mathrm{~m}^{3} / \mathrm{s}$. Esse resultado demonstra uma diferença de 5,09\% entre o valor obtido e o valor informado pelo Plano, mantendo a mesma média de diferença encontrada no período de cheia.

\subsubsection{Sub-bacia BD-30}

Para o segundo experimento, optou-se pela sub-bacia BD-30. O procedimento de levantamento do perímetro da sub-bacia e o reconhecimento da cobertura dos solos foi similar ao realizado na sub-bacia BD-36, porém, para que se possa ter mais exatidão ao fazer o reconhecimento da cobertura do solo, áreas estimadas e se alcançar um coeficiente de escoamento superficial mais preciso, optou-se por utilizar células de $5 \times 5$ metros.

Outra alteração feita em relação ao estudo anterior foi a caracterização no software AutoCAD, através de "layers", de uma quantidade maior de materiais de cobertura do solo (vias e calçadas, edificações residenciais, edificações comerciais, edificações institucionais, área permeável, pasto, terrenos impermeáveis e cursos d'água).

De acordo com o diagnóstico do Plano de Drenagem de Juiz de Fora (2011) o coeficiente de escoamento da sub-bacia BD-30 é de 0,53. O valor obtido com a ferramenta desenvolvida é 
de 0,52 , apresentando diferença de $1,8 \%$ no resultado final. Essa diferença se apresenta consideravelmente inferior a diferença encontrada na sub-bacia BD-36.

Considerando o tempo de retorno de 100 anos, o valor final encontrado para a vazão máxima da bacia " $Q$ " foi de $23,42 \mathrm{~m}^{3} / \mathrm{s}$. De acordo com o Plano de Drenagem de Juiz de Fora, o valor de " $Q$ " para a bacia BD-30 nos períodos de cheia é de $40,11 \mathrm{~m}^{3} / \mathrm{s}$. A diferença entre o valor encontrado pela ferramenta e o valor informado no plano de drenagem é de $41,61 \%$. Alterando o valor do tempo de retorno para 5 (período de seca), o valor da vazão máxima " $Q$ " passa a ser 13,95 $\mathrm{m}^{3} / \mathrm{s}$. De acordo com o plano de drenagem de Juiz de Fora, 0 valor de " $Q$ " para os períodos de seca é de $21,60 \mathrm{~m}^{3} / \mathrm{s}$, assim como na sub-bacia BD-36. Esse resultado demonstra uma diferença de $35,41 \%$ entre o valor obtido e o valor informado pelo Plano. Em razão da diferença de valores expressiva, o desenho desenvolvido no software AutoCAD e importado para o software Rhinoceros foi revisto, assim como todos os algoritmos desenvolvidos no Grasshopper, porém os valores se mantiveram, assim como as diferenças em relação ao Plano de Drenagem de Juiz de Fora. Tendo em vista a fórmula utilizada nos algoritmos, fiéis ao método racional, assim como os valores aceitáveis obtidos na simulação da sub-bacia BD-36, não se apresentou com clareza o motivo de tamanha discrepância em relação aos valores da sub-bacia BD-30. Não foi possível acessar a memória de cálculo do Plano de Drenagem de Juiz de Fora - Zona Norte, mas acredita-se, inclusive, que pode ter sido encontrado um ponto a ser revisto no mesmo. Optou-se por fazer uma nova simulação, em outra sub-bacia da Região Norte da cidade de Juiz de Fora, a sub-bacia BD-34.

\subsubsection{Sub-bacia BD-34}

O procedimento de levantamento do perímetro da sub-bacia e o reconhecimento da cobertura dos solos foi idêntico ao realizado na sub-bacia BD-30, lançando mão de células de $5 \times 5$ metros. Manteve-se também a caracterização da quantidade de materiais de cobertura do solo.

De acordo com o diagnóstico do Plano de Drenagem de Juiz de Fora (2011) o coeficiente de escoamento da sub-bacia BD-34 é de 0,34. O valor obtido com a ferramenta desenvolvida é de 0,34, apresentando resultado idêntico ao informado pelo Plano. 
O valor final encontrado, de 32,38, refere-se à vazão máxima da bacia " $Q$ " em $\mathrm{m}^{3} / \mathrm{s}$. De acordo com o Plano de Drenagem de Juiz de Fora, o valor de " $Q$ " para a bacia BD-34 nos períodos de cheia (tempo de retorno de 100 anos) é de $38,41 \mathrm{~m}^{3} / \mathrm{s}$. A diferença entre o valor encontrado pela ferramenta e o valor informado no plano de drenagem é de 15,69\%. Alterando o valor do tempo de retorno para 5, o valor da vazão máxima " $Q$ " passa a ser $19,28 \mathrm{~m}^{3} / \mathrm{s}$. De acordo com o Plano de Drenagem de Juiz de Fora, o valor de " $Q$ " para os períodos de seca é de $21,74 \mathrm{~m}^{3} / \mathrm{s}$, o que demonstra uma diferença de $11,3 \%$ entre o valor obtido e o valor informado pelo Plano.

\subsubsection{Resultados das verificações}

Todos os valores referentes ao coeficiente de escoamento superficial apresentaram variações percentuais baixas e, portanto, aceitáveis. Em relação aos valores encontrados para as vazões máximas, houve variação expressiva apenas nos resultados obtidos para a sub-bacia BD-30, tanto nos tempos de cheia quanto nos tempos de seca, conforme pode ser verificado na tabela 2 . Percebe-se que todos os valores encontrados foram inferiores aos valores informados pelo Plano de drenagem de Juiz de Fora. Essa alteração pode ser reflexo da dificuldade de identificação de cobertura dos solos de terrenos particulares encontrados nas três sub-bacias.

\section{Simulações com a ferramenta}

Serão apresentadas a seguir as simulações computacionais da utilização do asfalto poroso e telhado verde, práticas comuns do conceito de drenagem urbana conhecida como desenvolvimento urbano de baixo impacto, nas sub bacias selecionadas para este trabalho (BD-36, BD-30 e BD-34).

Ao promover as simulações, tem-se a intenção de verificar se os coeficientes de escoamento superficial e volume de vazões máximas de cada sub-bacia sofrerão alterações significativas, e dessa forma verificar a aplicabilidade dessas práticas do desenvolvimento urbano de baixo impacto como forma de combate às enchentes urbanas, assim como constatar a relevância da ferramenta como fornecedora de dados para elaboração de projetos de drenagem urbana. 


\subsection{Simulações com a utilização do asfalto poroso}

Como descrito anteriormente, toda a área das sub-bacias foi sobreposta por um grid, ora com $10 \times 10$ metros (BD-36), ora com $5 \times 5$ metros (BD-30 e BD-34), composto por um conjunto de células, onde cada célula representa determinado material de cobertura do solo. Entre os materiais, encontra-se o asfalto e a célula que o representa: "vias e calçadas". O valor atribuído ao coeficiente de escoamento das vias e calçadas é de 0,80 , referente ao asfalto convencional (ASCE, 1969). De acordo com Acioli (2005) valor do coeficiente do asfalto poroso é 0.05 .

Tabela 2 - Valores de coeficiente de escoamento e vazão máxima encontrados para as sub bacias.

\begin{tabular}{|c|c|c|c|c|c|}
\hline \multicolumn{2}{|l|}{ Valores finais - BD-36 } & \multicolumn{2}{|l|}{ Valores finais - BD-30 } & \multicolumn{2}{|l|}{ Valores finais - BD-34 } \\
\hline $\begin{array}{l}\text { Coeficiente de } \\
\text { superficial }\end{array}$ & Escoamento & $\begin{array}{l}\text { Coeficiente de } \\
\text { superficial }\end{array}$ & Escoamento & $\begin{array}{l}\text { Coeficiente } \\
\text { superficial }\end{array}$ & Escoamento \\
\hline Ferramenta & 0.42 & Ferramenta & 0.52 & Ferramenta & 0.34 \\
\hline $\begin{array}{l}\text { Plano de drenagem } \\
\text { de Juiz de Fora }\end{array}$ & 0.40 & $\begin{array}{l}\text { Plano de drenagem } \\
\text { de Juiz de Fora }\end{array}$ & 0.53 & $\begin{array}{l}\text { Plano de drenagem } \\
\text { de Juiz de Fora }\end{array}$ & 0.34 \\
\hline Variação & $5 \%$ & Variação & $1,8 \%$ & Variação & - \\
\hline $\begin{array}{l}\text { Vazão Máxima - } \\
\text { cheia (tempo de ret } \\
\text { anos) }\end{array}$ & $\begin{array}{l}\text { Períodos de } \\
\text { torno de } 100\end{array}$ & $\begin{array}{l}\text { Vazão Máxima - } \\
\text { cheia (tempo de ret } \\
\text { anos) }\end{array}$ & $\begin{array}{l}\text { Períodos de } \\
\text { torno de } 100\end{array}$ & $\begin{array}{l}\text { Vazão Máxima - Per } \\
\text { (tempo de retorno o }\end{array}$ & $\begin{array}{l}\text { dos de cheia } \\
100 \text { anos) }\end{array}$ \\
\hline Ferramenta & $34,43 \mathrm{~m}^{3} / \mathrm{s}$ & Ferramenta & $23,42 \mathrm{~m}^{3} / \mathrm{s}$ & Ferramenta & $32,38 \mathrm{~m}^{3} / \mathrm{s}$ \\
\hline $\begin{array}{l}\text { Plano de drenagem } \\
\text { de Juiz de Fora }\end{array}$ & $36,21 \mathrm{~m}^{3} / \mathrm{s}$ & $\begin{array}{l}\text { Plano de drenagem } \\
\text { de Juiz de Fora }\end{array}$ & $40,11 \mathrm{~m}^{3} / \mathrm{s}$ & $\begin{array}{l}\text { Plano de drenagem } \\
\text { de Juiz de Fora }\end{array}$ & $38,41 \mathrm{~m}^{3} / \mathrm{s}$ \\
\hline Variação & $4,91 \%$ & Variação & $41,61 \%$ & Variação & $15,69 \%$ \\
\hline $\begin{array}{l}\text { Vazão Máxima - F } \\
\text { seca }\end{array}$ & Períodos de & $\begin{array}{l}\text { Vazão Máxima - } \\
\text { seca }\end{array}$ & Períodos de & Vazão Máxima - Per & dos de seca \\
\hline Ferramenta & $20,50 \mathrm{~m}^{3} / \mathrm{s}$ & Ferramenta & $13,95 \mathrm{~m}^{3} / \mathrm{s}$ & Ferramenta & $19,28 \mathrm{~m}^{3} / \mathrm{s}$ \\
\hline $\begin{array}{l}\text { Plano de drenagem } \\
\text { de Juiz de Fora }\end{array}$ & $21,60 \mathrm{~m}^{3} / \mathrm{s}$ & $\begin{array}{l}\text { Plano de drenagem } \\
\text { de Juiz de Fora }\end{array}$ & $21,60 \mathrm{~m}^{3} / \mathrm{s}$ & $\begin{array}{l}\text { Plano de drenagem } \\
\text { de Juiz de Fora }\end{array}$ & $21,74 \mathrm{~m}^{3} / \mathrm{s}$ \\
\hline Variação & $5,09 \%$ & Variação & $35,41 \%$ & Variação & $11,30 \%$ \\
\hline
\end{tabular}

Fonte: Elaboração própria. 


\subsubsection{Asfalto poroso nas vias públicas da sub bacia BD-36}

Para efetuar a manipulação do revestimento de piso da sub bacia BD-36 e simulação da aplicação do asfalto poroso, deve-se alterar o valor do coeficiente de escoamento superficial " $C$ " das células "vias e calçadas". Após feita a alteração no valor do coeficiente de escoamento superficial vinculada às células das vias e calçadas, percebe-se também uma alteração do coeficiente de escoamento total da bacia. O valor do coeficiente de escoamento total baixou de 0,42 para 0,35 , o que representa uma redução de $16,6 \%$.

Como o valor " $\mathrm{C}$ " da fórmula do Método Racional foi alterada, o valor final da equação, referente à vazão máxima " $Q$ ", também sofre alterações. Considerando-se o tempo de retorno de 100 anos, o valor da vazão máxima foi reduzido de $34,43 \mathrm{~m}^{3} / \mathrm{s}$ para $28,83 \mathrm{~m}^{3} / \mathrm{s}$, apresentando queda de 16,26\%. Quando o tempo de retorno é reduzido para 5 anos, o valor da vazão máxima é reduzido de $20,50 \mathrm{~m}^{3} /$ para $17,17 \mathrm{~m}^{3} / \mathrm{s}$, o que representa uma queda de 16,24\% em relação à situação anterior.

\subsubsection{Asfalto poroso nas vias públicas da sub-bacia BD-30}

O procedimento para efetuar a manipulação do revestimento de piso da sub-bacia BD-30 e simulação da aplicação do asfalto poroso, é o mesmo aplicado na sub-bacia BD-36. Após feita a alteração no valor do coeficiente de escoamento superficial vinculado às células das vias e calçadas, percebe-se também uma alteração do coeficiente de escoamento total da bacia, assim como aconteceu na sub-bacia BD-36. O valor do coeficiente de escoamento total baixou de 0.52 para 0.41 , representando uma redução de $21,15 \%$.

Considerando-se o tempo de retorno de 100 anos, o valor da vazão máxima foi reduzido de $23,42 \mathrm{~m}^{3} / \mathrm{s}$ para $18,51 \mathrm{~m}^{3} / \mathrm{s}$, apresentando queda de $21 \%$. Ao se reduzir o tempo de retorno para 5 anos, o valor da vazão máxima é reduzido de $13,95 \mathrm{~m}^{3} /$ para $11,02 \mathrm{~m}^{3} / \mathrm{s}$, o que representa uma queda de $21 \%$ em relação à situação anterior.

\subsubsection{Asfalto poroso nas vias públicas da sub-bacia BD-34}

Após feito o mesmo procedimento aplicado nas duas sub-bacias anteriores, o valor do coeficiente de escoamento total da sub-bacia BD-34 baixou de 0.34 para 0.31 , 
representando uma redução de $8,82 \%$. Considerando-se o tempo de retorno de 100 anos, o valor da vazão máxima foi reduzido de $32,38 \mathrm{~m}^{3} / \mathrm{s}$ para $30,12 \mathrm{~m}^{3} / \mathrm{s}$, apresentando queda de 6,69\% em relação à situação anterior à implantação do piso permeável. Quando o tempo de retorno é reduzido para 5 anos, o valor da vazão máxima é reduzido de $19,28 \mathrm{~m}^{3}$ / para $17,94 \mathrm{~m}^{3} / \mathrm{s}$, o que representa uma queda de $6,95 \%$ em relação à situação anterior, tendo a cobertura do solo com asfalta convencional.

\subsubsection{Considerações sobre a aplicação do asfalto poroso}

Ao se analisar a redução do coeficiente de escoamento superficial total e a redução da vazão máxima de cada sub-bacia (BD-36, BD-30 e BD-34), através da simulação da troca do asfalto convencional pelo asfalto poroso como material de cobertura do solo das vias e calçadas, percebe-se que a alteração se mostra efetiva e considerável, conforme pode ser visto na tabela 3. Quando esses valores são relacionados com a percentagem de cada sub bacia coberta por vias e calçadas $(8,85 \%, 14,15 \%$ e $3,06 \%$, respectivamente) fica ainda mais evidente. Em áreas ainda mais urbanizadas, onde a probabilidade de existir uma percentagem ainda maior da sub-bacia coberta por vias e calçadas, essa redução tende a se mostrar ainda mais significativa, pois será ainda maior a percentagem da sub-bacia que terá seu coeficiente de escoamento reduzido. A solução se mostra eficaz no combate às enchentes urbanas e apresenta-se como uma solução atrativa, sobretudo nas áreas urbanas consolidadas, onde não há possibilidade de aplicação de soluções e práticas de drenagem de grande escala, como bacias de detenção ou retenção.

\subsection{Simulações com telhado verde}

Para efetuar a simulação da aplicação do telhado verde nas edificações comerciais das subbacias, foi necessário identificá-las através de visitas aos bairros e análises através do aplicativo Google Earth e Street View, da empresa Google. Após reconhecimento das edificações foi feita a caracterização de cada célula desenvolvida no software AutoCAD de acordo com o uso das edificações, conforme descrito anteriormente. O valor descrito para " $C$ " em áreas urbanas é de 0,85, enquanto telhados verdes representam um coeficiente de escoamento " $C$ " de 0,30, o que representa uma diferença de 64,70\%. 
De acordo com o que foi descrito anteriormente, a sub-bacia BD-36, primeira sub-bacia simulada neste trabalho, não recebeu diferenciação entre os usos de suas edificações, impossibilitando a simulação da aplicação de telhados verdes nas edificações de uso comercial. Já as duas sub-bacias seguintes, BD-30 e BD-34, possuem a caracterização e diferenciação de células de acordo com o tipo de edificação e seu uso, possibilitando a elaboração das simulações e manipulações de dados.

Tabela 3 - Valores de coeficiente de escoamento e vazão máxima encontrados na simulação de aplicação do asfalto poroso nas vias das sub-bacias.

\begin{tabular}{|c|c|c|c|c|c|}
\hline \multicolumn{2}{|c|}{ Asfalto Poroso - BD-36 } & \multicolumn{2}{|c|}{ Asfalto Poroso - BD-30 } & \multicolumn{2}{|c|}{ Asfalto Poroso - BD-34 } \\
\hline $\begin{array}{l}\text { Coeficiente de } \\
\text { superficial }\end{array}$ & Escoamento & $\begin{array}{l}\text { Coeficiente de } \\
\text { superficial }\end{array}$ & Escoamento & $\begin{array}{l}\text { Coeficiente de } \\
\text { superficial }\end{array}$ & Escoamento \\
\hline Ferramenta & 0.42 & Ferramenta & 0.52 & Ferramenta & 0.34 \\
\hline $\begin{array}{l}\text { Aplicação do } \\
\text { asfalto poroso }\end{array}$ & 0.35 & $\begin{array}{l}\text { Aplicação do asfalto } \\
\text { poroso }\end{array}$ & 0.41 & $\begin{array}{l}\text { Aplicação do asfalto } \\
\text { poroso }\end{array}$ & 0.31 \\
\hline Redução & $16,6 \%$ & Redução & $21,15 \%$ & Redução & $8,82 \%$ \\
\hline $\begin{array}{l}\text { Vazão Máxima - } \\
\text { cheia }\end{array}$ & Períodos de & $\begin{array}{l}\text { Vazão Máxima - } \\
\text { cheia }\end{array}$ & Períodos de & $\begin{array}{l}\text { Vazão Máxima - } \\
\text { cheia }\end{array}$ & Períodos de \\
\hline Ferramenta & $34,43 \mathrm{~m}^{3} / \mathrm{s}$ & Ferramenta & $23,42 \mathrm{~m}^{3} / \mathrm{s}$ & Ferramenta & $32,38 \mathrm{~m}^{3} / \mathrm{s}$ \\
\hline $\begin{array}{l}\text { Aplicação do } \\
\text { asfalto poroso }\end{array}$ & $28,83 \mathrm{~m}^{3} / \mathrm{s}$ & $\begin{array}{l}\text { Aplicação do asfalto } \\
\text { poroso }\end{array}$ & $18,51 \mathrm{~m}^{3} / \mathrm{s}$ & $\begin{array}{l}\text { Aplicação do asfalto } \\
\text { poroso }\end{array}$ & $30,12 \mathrm{~m}^{3} / \mathrm{s}$ \\
\hline Redução & $16,26 \%$ & Redução & $21 \%$ & Redução & $6,69 \%$ \\
\hline $\begin{array}{l}\text { Vazão Máxima - } \\
\text { seca }\end{array}$ & Períodos de & $\begin{array}{l}\text { Vazão Máxima - } \\
\text { seca }\end{array}$ & Períodos de & $\begin{array}{l}\text { Vazão Máxima - } \\
\text { seca }\end{array}$ & Períodos de \\
\hline Ferramenta & $20,50 \mathrm{~m}^{3} / \mathrm{s}$ & Ferramenta & $13,95 \mathrm{~m}^{3} / \mathrm{s}$ & Ferramenta & $19,28 \mathrm{~m}^{3} / \mathrm{s}$ \\
\hline $\begin{array}{l}\text { Aplicação do } \\
\text { asfalto poroso }\end{array}$ & $17,17 \mathrm{~m}^{3} / \mathrm{s}$ & $\begin{array}{l}\text { Aplicação do asfalto } \\
\text { poroso }\end{array}$ & $11,02 \mathrm{~m}^{3} / \mathrm{s}$ & $\begin{array}{l}\text { Aplicação do asfalto } \\
\text { poroso }\end{array}$ & $17,94 \mathrm{~m}^{3} / \mathrm{s}$ \\
\hline Redução & $16,24 \%$ & Redução & $21 \%$ & Redução & $6,96 \%$ \\
\hline
\end{tabular}

Fonte: Elaboração própria.

\subsubsection{Simulações com telhado verde nas edificações comerciais da sub-bacia BD-30}

Para efetuar a simulação da aplicação de telhados verdes nas edificações comerciais da subbacia BD-30 deve-se alterar o valor do coeficiente de escoamento superficial " $C$ " às células "edificações comerciais". O valor vinculado à essas células inicialmente é de 0.80 , valor 
referente ao coeficiente de escoamento superficial de áreas urbanizadas. Segundo Baldessar (2012) o valor do coeficiente de escoamento superficial do telhado verde é de 0.30 , apresentando diferença de $64,70 \%$.

Após feita a alteração no valor do coeficiente de escoamento superficial vinculada às edificações comerciais, percebe-se uma alteração do coeficiente de escoamento total da bacia. O valor do coeficiente de escoamento total baixou de 0.52 para 0.50 , o que representa uma redução de 3,84\%. Considerando-se o tempo de retorno de 100 anos, o valor da vazão máxima foi reduzido de $23.42 \mathrm{~m}^{3} / \mathrm{s}$ para $22.49 \mathrm{~m}^{3} / \mathrm{s}$, apresentando queda de 3,97\% em relação à situação anterior à implantação do telhado verde nas edificações de uso comercial. Reduzindo-se o tempo de retorno para 5 anos, o valor da vazão máxima baixa de $13,95 \mathrm{~m}^{3} /$ para $13,39 \mathrm{~m}^{3} / \mathrm{s}$, o que representa uma queda de $4,01 \%$ em relação à situação anterior.

\subsubsection{Simulações com telhado verde nas edificações comerciais da sub-bacia BD-34}

O procedimento para efetuar a manipulação do revestimento da cobertura das edificações comerciais da sub-bacia BD-34 e simulação da aplicação do telhado verde, é o mesmo aplicado na sub-bacia BD-30. O valor do coeficiente de escoamento total baixou de 0.34 para 0.33 , representando uma queda de $2,94 \%$. Considerando-se o tempo de retorno de 100 anos, o valor da vazão máxima foi reduzido de $32,38 \mathrm{~m}^{3} / \mathrm{s}$ para $31,83 \mathrm{~m}^{3} / \mathrm{s}$, apresentando queda de 1,69\% em relação à situação anterior à implantação do telhado verde nas edificações comerciais. Quando o tempo de retorno é reduzido para 5 anos, o valor da vazão máxima é reduzido de $19,28 \mathrm{~m}^{3} /$ para $18,95 \mathrm{~m}^{3} / \mathrm{s}$, o que representa uma queda de $1,71 \%$ em relação à situação anterior.

\subsubsection{Considerações sobre a aplicação do telhado verde nas edificações comerciais}

Constata-se que a aplicação de telhados verdes na cobertura de edificações comerciais pode proporcionar impacto efetivo na redução do escoamento superficial nas sub-bacias, conforme pode ser visto na tabela 4. Salienta-se que a quantidade de edificações comerciais, assim como a área total que ocupam dentro de uma sub-bacia, é determinante para que a redução do escoamento superficial seja considerável no combate às enchentes 
urbanas. A área coberta por edificações de uso comercial na sub-bacia BD-30 é de 3,8\%, enquanto na sub-bacia BD-34 é de 1,05\%.

Tabela 4 - Valores de coeficiente de escoamento e vazão máxima encontrados na simulação da aplicação do telhado verde nas coberturas das edificações comerciais das sub-bacias BD-30 e BD-34

Telhado Verde - BD-30

Telhado Verde - BD-34

\begin{tabular}{|c|c|c|c|}
\hline \multicolumn{2}{|c|}{ Coeficiente de Escoamento superficial } & \multicolumn{2}{|c|}{ Coeficiente de Escoamento superficial } \\
\hline Ferramenta & 0.52 & Ferramenta & 0.34 \\
\hline Aplicação do telhado verde & 0.50 & $\begin{array}{l}\text { Aplicação do telhado } \\
\text { verde }\end{array}$ & 0.33 \\
\hline Redução & $3,84 \%$ & Redução & $2,94 \%$ \\
\hline \multicolumn{2}{|c|}{ Vazão Máxima - Períodos de cheia } & \multicolumn{2}{|c|}{ Vazão Máxima - Períodos de cheia } \\
\hline Ferramenta & $23,42 \mathrm{~m}^{3} / \mathrm{s}$ & Ferramenta & $32,38 \mathrm{~m}^{3} / \mathrm{s}$ \\
\hline Aplicação do telhado verde & $22,49 \mathrm{~m}^{3} / \mathrm{s}$ & $\begin{array}{l}\text { Aplicação do telhado } \\
\text { verde }\end{array}$ & $31,83 \mathrm{~m}^{3} / \mathrm{s}$ \\
\hline Redução & $3,97 \%$ & Redução & $1,69 \%$ \\
\hline \multicolumn{2}{|c|}{ Vazão Máxima - Períodos de seca } & \multicolumn{2}{|c|}{ Vazão Máxima - Períodos de seca } \\
\hline Ferramenta & $13,95 \mathrm{~m}^{3} / \mathrm{s}$ & Ferramenta & $19,28 \mathrm{~m}^{3} / \mathrm{s}$ \\
\hline Aplicação do telhado verde & $13,39 \mathrm{~m}^{3} / \mathrm{s}$ & $\begin{array}{l}\text { Aplicação do telhado } \\
\text { verde }\end{array}$ & $18,95 \mathrm{~m}^{3} / \mathrm{s}$ \\
\hline Redução & $4,01 \%$ & Redução & $1,71 \%$ \\
\hline
\end{tabular}

Fonte: Elaboração própria.

\section{Conclusões}

Este trabalho aborda a associação de conceitos paramétricos com a drenagem das águas pluviais urbanas. Optou-se por desenvolver uma ferramenta algorítmico-paramétrica capaz de fornecer dados relacionados aos índices de escoamento superficial e de vazão máxima de determinada bacia hidrográfica. Durante o processo de construção e avaliação da ferramenta, identificaram-se pontos positivos e pontos frágeis da mesma. 
Constatou-se a simplicidade de elaborar simulações com o auxílio da ferramenta, sejam elas relacionadas à situação atual das sub-bacias quanto à simulação da aplicação de determinados materiais como cobertura do solo. Além disso, a ferramenta traz como contribuição a possibilidade de verificação do coeficiente de escoamento superficial e da vazão máxima em qualquer parte da sub-bacia, e não somente na parte mais a jusante. As simulações e calibrações elaboradas nesse trabalho indicaram uma precisão aceitável da ferramenta, principalmente se considerarmos que os dados apontados pelo Plano de Drenagem de Juiz de Fora, elaborado pela Prefeitura Municipal de Juiz de Fora, utilizado aqui como parâmetro de comparação e calibração, também podem ter suas imprecisões.

O grid utilizado nas simulações para identificação da cobertura do solo, ora se apresenta com $10 \times 10 \mathrm{~m}$, ora com $5 \times 5 \mathrm{~m}$, e permite uma leitura das sub-bacias de forma satisfatória. Esses valores podem ser alterados na construção da imagem no software AutoCAD, e quanto menor o tamanho das células, maior a resolução e, consequentemente, maior a precisão na leitura.

Entre os pontos frágeis, pode-se destacar o processo trabalhoso de reconhecimento dos materiais de cobertura do solo, assim como sua reprodução no software AutoCAD, através de figuras geométricas denominadas aqui como células. Além disso, a ferramenta apresenta limitações ao não reconhecer o relevo das sub-bacias, assim como não considera as possíveis fraturas tectônicas e litológicas das mesmas. Pretende-se em trabalhos posteriores tornar esse reconhecimento possível, além da automatização do processo de identificação da cobertura dos solos, conferindo ainda mais atratividade à ferramenta.

De forma geral a ferramenta demonstra desempenho satisfatório e cumpre o papel proposto neste momento, possibilitando ainda que este trabalho se apresente como ponto de partida para pesquisas futuras.

\section{Referências}

ACIOLI, Laura Albuquerque. Estudo experimental de pavimentos permeáveis para o controle do escoamento superficial na fonte. Dissertação (Mestrado em Engenharia) - Pós-Graduação em Recursos Hídricos e Saneamento Ambiental da Universidade Federal do Rio Grande do Sul, 2005.

ARAÚJO, Paulo Roberto; TUCCI, Carlos Eduardo Morelli e GOLDENFUM, Joel. Avaliação da eficiência dos pavimentos permeáveis na redução do escoamento superficial. RBRH - Revista Brasileira dos Recursos Hídricos, setembro 2000, vol. 5, oㅡ 3, p. 21-29. 
ASCE. Design and construction of sanitary and storm sewers. Manuals and Reports of Engineering Pratice. $\mathrm{n}$ 은 37. New York, 1969.

BALDESSAR, Silvia Maria Nogueira. Telhado verde e sua contribuição na redução da vazão da água pluvial escoada. Dissertação (Mestrado em Construção Civil), Universidade Federal do Paraná, Setor de Tecnologia, Programa de Pós-Graduação em Engenharia de Construção Civil, 2012.

CANHOLI, Aluísio Pardo. Drenagem urbana e controle de enchentes. São Paulo: Oficina de Textos. 2005. ISBN 978-85-86238-43-7

CASTRO, William et al. Plano de drenagem de Juiz de Fora. Prefeitura Municipal de Juiz de Fora, 2011.

CESAMA. A Cidade De Juiz De Fora. Disponível em: https://www.cesama.com.br/?pagina=hidrografia. Acesso em 02 de outubro de 2018

CORMIER, Nathaniel S. e PELLEGRINO, Paulo Renato Mesquita. Infra-estrutura verde: uma estratégia paisagística para a água urbana. Revista Paisagem e Ambiente, 2008, nㅇ2, 25, 125-142.

IBGE. Cidades - Juiz de Fora. Disponível em: http://cod.ibge.gov.br/7PF. Acesso em 02 de outubro de 2018.

JUAN, Andrew; HUGHES, Christina; FANG, Zheng and BEDIENT, Phillip. Hydrologic Performance of WatershedScale Low-Impact Development in a High-Intensity Rainfall Region. Journal of Irrigation and Drainage Engineering, April 2017, vol. 143, № 4.

LIMA, Fernando Tadeu de Araújo et al. Citymetrics: sistema (para)métrico para análise e otimização de configurações urbanas. Oculum Ensaios, 2019, vol. 16, no 2, p. 409-427. http://dx.doi.org/10.24220/2318-0919v1 6n2a4163

LIMA, Fernando Tadeu de Araújo. MÉTRICAS URBANAS: Sistema (para)métrico para análise e otimização de configurações urbanas de acordo com métricas de avaliação de desempenho. Tese (Doutorado em Urbanismo) - PROURB, Faculdade de Arquitetura e Urbanismo da Universidade Federal do Rio de Janeiro, 2017.

MACHADO, Pedro José de Oliveira e CUNHA, Sandra Baptista da. Juiz de fora: inundações, saneamento e ordenamento territorial. Revista Geográfica de América Central, 2011, vol. 2, no 47E, p. 1-15.

MARTINS, Lorraine Campos. Vazão máxima em pequena bacia hidrográfica parcialmente urbanizada em Uberlândia - MG. Dissertação (Mestrado em Meio Ambiente e Qualidade Ambiental) - Universidade Federal de Uberlândia, 2017.

PEREIRA, Ticiana Muniz. Avaliação preliminar da capacidade de escoamento do trecho canalizado no terço superior do Córrego do São Pedro com auxílio da ferramenta HEC-RAS. Trabalho Final de Graduação (Engenharia Sanitária e Ambiental) - Universidade Federal de Juiz de Fora, 2015.

PINTO, Liliane Lopes Costa Alves. O desempenho de pavimentos permeáveis como medida mitigadora da impermeabilização do solo urbano. Tese (Doutorado em engenharia) - Universidade de São Paulo, 2011.

REIS, Patrícia; PARIZZI, Maria Giovana; MAGALHÃES, Danilo Marques e MOURA, Ana Clara. O escoamento superficial como condicionante de inundações em Belo Horizonte, MG: Estudo de caso da sub-bacia Córrego do Leitão, bacia do Ribeirão Arrudas. Revista Brasileira de Geociências, 2012, vol. 31, no 1, p. 31-46.

RIBEIRO, Maria Janete Pereira; D'LAURA, Aluztane; ANDRADE, Darline Nascimento e SAMPAIO, Reijane Brito. Os impactos ambientais na bacia hidrográfica do Rio do Cobre em Salvador, Bahia: utilização do geoprocessamento na avaliação de impactos ambientais. In: SIMPÓSIO BRASILEIRO DE RECURSOS HÍDRICOS, Bento Gonçalves. Anais. Bento Gonçalves: ABRH, 2013.

SANCHES, Leonardo. Parametrização e sistemas generativos como apoio à tomada de decisões em projetos de arquitetura aplicados à legislação urbana da cidade de juiz de fora. Dissertação (Mestrado em Ambiente Construído) - Universidade Federal de Juiz de Fora, 2017.

SOUZA, Christopher Freire; CRUZ, Marcus Aurélio Soares; TUCCI, Carlos Eduardo Morelli. Desenvolvimento Urbano de Baixo Impacto: Planejamento e Tecnologias Verdes para a Sustentabilidade das Águas Urbanas. Revista Brasileira de Recursos Hídricos, 2012, vol.17, $\mathrm{n}^{\circ} 2$. 
SOUZA, Graziella Martinez; ROMUALDO, Sanderson dos Santos. Inundações urbanas: a percepção sobre a problemática socioambiental pela comunidade do bairro jardim natal - juiz de fora (mg). XIII Simpósio Brasileiro de Geografia Física Aplicada. Universidade Federal de Viçosa, 2009.

TOMAZ, Plínio. Capítulo 02: Método Racional. Curso de Manejo de águas pluviais. Serviço Autônomo de Água e Esgoto (SAAE), Guarulhos, 2013.

TUCCI, Carlos Eduardo Morelli. Coeficientes de escoamento e vazão máxima de bacias urbanas. Revista Brasileira de Recursos Hídricos, 2000, vol.5, no⒈

TUCCI, Carlos Eduardo Morelli. Gestão de águas pluviais urbanas. Ministério das Cidades, Brasília, 2006.

XIE, Y.M., ZUO Z.H., HUANG, X., TANG, J.W., ZHAO, B., FELICETTI, P. Architecture and Urban Design through Evolutionary Structural Optimisation Algorithms. Proceedings of the International Symposium on Algorithmic Design for Architecture and Urban Design. March 2011, Tokyo, Japan. 